\title{
Fractioned High Pressure Extraction of Anthocyanins from Elderberry (Sambucus nigra L.) Pomace
}

\author{
Inês J. Seabra • Mara E. M. Braga • \\ Maria T. P. Batista $\cdot$ Hermínio C. de Sousa
}

Received: 10 April 2008/Accepted: 5 August 2008

(C) Springer Science + Business Media, LLC 2008

\begin{abstract}
Fractionated high pressure extractions from dry and in natura elderberry pomace were performed in order to obtain anthocyanin rich extracts. Experiments were carried out using $\mathrm{CO}_{2}$ supercritical fluid extraction followed by enhanced solvent extraction (ESE) with $\mathrm{CO}_{2} /$ EtOH- $\mathrm{H}_{2} \mathrm{O}$ mixtures $(1-100 \%, v / v)$, to obtain anthocyanin rich fractions in the second step, at $313 \mathrm{~K}$ and $\sim 20 \mathrm{MPa}$. Higher extract yields, anthocyanin contents and antioxidant activities occurred by the presence of water, both in the raw material and in the solvent mixture. The $\mathrm{CO}_{2}$ dissolved in the ESE solvent mixture favored either anthocyanin contents or antioxidant activities, which were not directly related. Comparing to the literature data for elderberries and grapes, these fractions had higher anthocyanins contents. From these results, an added economical value to this agroindustrial residue is proposed, using solvents and techniques "generally regarded as safe" in the food and pharmaceutical industries.
\end{abstract}

Grants support: I. J. Seabra and M. E. M. Braga acknowledge Fundação para a Ciência e Tecnologia (FCT-MCTES) for the doctoral and post-doctoral fellowships, respectively (SFRH/BD/29133/2006 and SFRH/BPD/21076/2004).

I. J. Seabra $\cdot$ M. E. M. Braga $\cdot$ H. C. de Sousa $(\square)$

CIEPQPF, Department of Chemical Engineering,

University of Coimbra,

3030-790, Coimbra, Portugal

e-mail: hsousa@eq.uc.pt

I. J. Seabra

ESAC, Politechnic Institute of Coimbra,

Bencanta,

3040-316, Coimbra, Portugal

M. T. P. Batista

CEF, Pharmacognosy Laboratory, Faculty of Pharmacy,

University of Coimbra,

3000-295, Coimbra, Portugal
Keywords Elderberry pomace - Anthocyanins . Antioxidants $\cdot$ Enhanced solvent extraction

\section{Introduction}

Presently, one of the most important trends in food and pharmaceutical industries is the growing demand for valuable natural sources of antioxidant compounds. Among common fruits and vegetables, elderberry (Sambucus nigra L.) is one of the richest in total phenolics and anthocyanins and, consequently, in antioxidant capacity (Bermúdez-Soto and Tomás-Barberan 2004; Wu et al. 2004). Cyanidin 3glucoside $(\mathrm{CyG})$ and cyanidin 3-sambubioside (CyS) are the main anthocyanins present (Braga et al. 2002) and quercetin 3-rutinoside (rutin) is the most representative flavonol (Bermúdez-Soto and Tomás-Barberan 2004; Fig. 1).

Most part of the literature focus essentially on elderberry fruit studies and a few work has been devoted to elderberry pomace regardless of its high anthocyanin content (75-98\% of total berry anthocyanins) when compared to its weight (25-40\% of total berry weight; Brønnum-Hansen et al. 1985). Despite its significant potential value, elderberry pomace does not own an important economic high value as it is traditionally used as animal feed or as an organic fertilizer. However, with some additional and proper processing, this byproduct could be easily transformed, from a residual low-value status into a very interesting high-value one, for consumer-accepted uses in food, cosmetic, and pharmaceutical industries.

Anthocyanins are polar molecules which are normally extracted from raw plant tissues by conventional solvent extraction (CSE) methodologies, using polar solvents slightly acidified with acids or sulfites. For some applications, high pressure extraction processes, like supercritical fluid extraction 


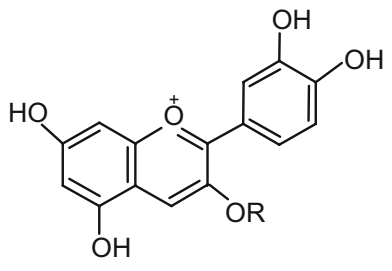

(1)

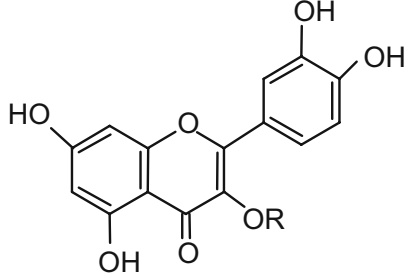

(2)
Fig. 1 Main flavonoids present in elderberries: (1) cyanidin 3-glucoside (R-glucose) and cyanidin 3-sambubioside (R-xylose-glucose); (2) quercetin 3-rutinoside (R-rutinose)

(SFE) and enhanced solvent extraction (ESE), already proved to represent valuable alternatives to CSE. SFE is an attractive "tunable" technique which may remove selectively various active constituents from plant matrices. Moreover, it can be particularly attractive for the extraction of antioxidants and anthocyanins because it may avoid their thermal degradation, and due to the absence of light and oxygen, it can prevent oxidation reactions (Díaz-Reinoso et al. 2006). In food and pharmaceutical applications, $\mathrm{CO}_{2}$ is the most employed supercritical solvent. The main drawbacks of $\mathrm{CO}_{2}$ are its nonpolar nature and its inability to extract high molecular weight compounds which might limit the extraction performance. Even though the addition of suitable cosolvents is the most frequent employed strategy to overcome these problems, a more recent employed approach is its association with other methodologies, such as ESE. ESE involves the use of $\mathrm{H}_{2} \mathrm{O}$ or organic solvents at considerable elevated temperatures $(313-473 \mathrm{~K})$ and pressures $(3.3-20.3 \mathrm{MPa})$. It offers the possibility to perform efficient and "enhanced" extractions due to its improved characteristics in terms of mass transfer and of solvating properties, which can even be improved by the utilization of gas-expanded liquids, obtained upon the dissolution of $\mathrm{CO}_{2}$ in $\mathrm{H}_{2} \mathrm{O}$ or in an organic solvent. This method takes advantage of the beneficial combination between typical liquids solvation properties and the advantageous transport properties of supercritical fluids (Chamblee et al. 2004), and it was already applied to the extraction of polar solutes (Yuan and Olesik 1997). Another unique and potentially useful property of $\mathrm{CO}_{2}$-aqueous and $\mathrm{CO}_{2}$-alcohol gas-expanded liquids is the generation of in situ carbonic acid and alkyl carbonic acid, respectively (Towes et al. 1995; West et al. 2001). In anthocyanin extraction, this fact can be an important advantage: there will be a temporary reduction in the extraction medium $\mathrm{pH}$ value, and this will increase anthocyanin stability and cell membrane permeability, leading to higher diffusivities (Türker and Erdoğdu 2006; Norton and Sun 2008). Moreover, it also can inactivate unwanted enzymes (Kamat et al. 1995; Norton and Sun 2008) and microorganisms (Foster et al. 2003) that may destroy these pigments (Delgado-Vargas and Paredes-López 2003; GarciaPalazon et al. 2004). On the other hand, the presence of undesired compounds in several vegetal matrixes, which may be coextracted or which may interfere negatively with the extraction of desired substances, decreasing extraction yield and selectivity, is a typical situation in natural products extraction methodologies (conventional and supercritical). A common way to overcome this situation is to employ extraction fractionated procedures (Pasquel et al. 2000; Reverchon 1997; Reverchon et al. 1999), using different solvent mixtures at different stages of the extraction process.

In this work, we explored the use of high-pressure fractioned extraction of elderberry pomace, using environmental friendly and food- or pharmaceutical-accepted solvents and techniques, in order to obtain anthocyaninrich extracts which can be used as natural colorants, dietary supplements, or phytochemical products. For all extraction experiments, a $\mathrm{CO}_{2}$ SFE was employed in a first extraction step and, subsequently, different $\mathrm{CO}_{2}-\mathrm{EtOH}-\mathrm{H}_{2} \mathrm{O}$ mixtures were employed in an ESE step. The influence of the polar ESE solvent mixture composition and of the raw material humidity were studied concerning extract yield, anthocyanin content, and antioxidant activity and compared to the results obtained by CSE.

\section{Materials and Methods}

\section{Raw Material}

In natura elderberries, provided by Cooperativa Agrícola do Vale do Varosa (Tarouca, Portugal), were collected in August 2004 according to Neto and Monteiro (2002) and stored under vacuum at $255 \mathrm{~K}$. Elderberry pomace was obtained by mechanical pressing (Hafico, Neuss, Germany) and dehydrated in a fluidized bed dryer (MK II, Sherwood Scientific, Cambridge, England) at $308 \mathrm{~K}$, in the absence of light, for $12 \mathrm{~h}$. Pomace was milled in a grinder (Braun, KSM 2, Kronberg, Germany) for 2 min, conditioned under vacuum at $255 \mathrm{~K}$, and its $\mathrm{H}_{2} \mathrm{O}$ content was determined gravimetrically (triplicate assays).

\section{Chemicals}

Carbon dioxide (99.998\%, Praxair, Madrid, Spain), EtOH (99.5\%, Panreac Quimica SA, Barcelona, Spain), and distilled $\mathrm{H}_{2} \mathrm{O}$ were used for the extraction experiments. Chemicals or solvents employed for extract analyses were: EtOH (P.A.), MeOH (Lichrosolv), formic acid (98-100\%), hydrochloric acid (P.A.), glacial acetic acid (P.A.), $n$-hexane (96\%), and ethyl acetate $(99.5 \%)$ purchased from Merck (Darmstadt, Germany), p-anysaldehyde (Sigma-Aldrich Inc., St. Louis, MO, USA), 2-aminoethyl diphenylborinate (97\%, Fluka, Steinheim, Germany), 2,2-diphenyl-1-picrylhydrazyl ( $\sim 90 \%$, Sigma-Aldrich Inc., Steinheim, Germany), and 
Ultra pure Milli Q water. Standards used for Thin Layer Chromatography (TLC) analyses were quercetin dehydrate $(\geq 98 \%)$, rutin hydrate $(\geq 95 \%)$, D- $(+)$-catechin hydrate (98\%), and gallic acid ( $\geq 98 \%)$, purchased from SigmaAldrich Inc. (Steinheim, Germany) and (-)-epicatechin ( $\geq 90 \%$, Fluka, Buchs, Switzerland). Standards used for High-Performance Liquid Chromatography (HPLC) analysis were cyanidin 3-glucoside chloride (analytical grade, Extrasynthèse, Genay, France) and rutin (extra pure, Merck, Darmstadt, Germany).

\section{Conventional Solvent Extractions}

These extractions were carried out using either an $\mathrm{EtOH}-\mathrm{H}_{2} \mathrm{O}$ $(8: 2, v / v)$ mixture or $\mathrm{H}_{2} \mathrm{O}$, at $313 \mathrm{~K}$. Dried elderberry pomace was homogenized using an Ultra-turrax (Ystral, D79282, Ballrechten-Dottingen, Germany) slowly increasing the rotational velocity from 8000 to $24,000 \mathrm{rpm}$, during the $\sim 3$ min extraction time, and employing a 1:10 (w/v) solid/ solvent ratio. The resulting slurry was then centrifuged (3,000 rpm, $15 \mathrm{~min})$ and filtered. The filter cake was reextracted for four times, until depletion of its anthocyanin characteristic color, and filtrates were combined and concentrated using a rotary evaporator (BÜCHI Rotavapor R-114, Flawil, Switzerland) at $313 \mathrm{~K}$. Later, extracts were lyophilized (FTS Systems Inc., N.Y., USA) and kept at 255 K. All procedures were made in the absence of light. The experimental conditions employed are reported in Table 1.

\section{Fractioned High Pressure Extractions}

These extractions were carried out using the apparatus presented in Fig. 2. Liquid $\mathrm{CO}_{2}$ was delivered to the extraction cell using a high pressure liquid compressor (maximum pressure of $30 \mathrm{MPa}$ ) and $\mathrm{EtOH}, \mathrm{EtOH}-\mathrm{H}_{2} \mathrm{O}$ $(8: 2, v / v)$ or $\mathrm{H}_{2} \mathrm{O}$ were delivered by a high pressure liquid pump (L-6200A, Hitachi, Merck, Darmstadt, Germany); solid/solvent ratios utilized are reported in Table 1. A stainless steel extraction cell $(\sim 30 \mathrm{~mL})$ was filled with elderberry pomace in three layers separated by glass beads (4 mm diameter), in order to achieve a uniform distribution of the solvent flow and a reduction of the dead space in the cell. Cotton wool was placed on both endings of the cell, to prevent line obstructions. Extraction cell was placed into a water bath with temperature controlled by an immersion circulator $( \pm 0.1 \mathrm{~K}, \mathrm{DC} 30$, Thermo Haake, Karlsruhe, Germany) and pressure was maintained by a back-pressure regulator (26-1762-24-090, Tescom, Selmsdorf, Germany) and measured by a pressure transducer (C204, Setra, Boxborough, MA, USA). Extracts were recovered in a recovering flask and a trap, placed in an ice bath, and the expanded $\mathrm{CO}_{2}$ flow was measured by a wet gas meter (DM3C ZE 1411, G.H. Zeal Ltd., London, England). A two-step fractioned high-pressure extraction methodology was employed, comprising: (1) a first $\mathrm{CO}_{2}$ SFE step in order to remove the low polarity $\mathrm{CO}_{2}$-soluble compounds (15 min static +40 min dynamic period); tubing line was cleaned with EtOH; (2) a second ESE step (45 min), in order to extract polar compounds like anthocyanins, and wherein $\mathrm{CO}_{2}$ and/or EtOH, EtOH- $\mathrm{H}_{2} \mathrm{O}(8: 2, v / v)$ or $\mathrm{H}_{2} \mathrm{O}$ were introduced into the system; different amounts of $\mathrm{EtOH}$ and $\mathrm{EtOH}-\mathrm{H}_{2} \mathrm{O}(90 \%$ and $100 \%, v / v)$ were assayed for in natura and for dried elderberry pomace. These solvent mixtures will be named ethanolic solvents. $\mathrm{CO}_{2}$ and $\mathrm{H}_{2} \mathrm{O}$ mixtures were also assayed with dried elderberry pomace, employing different percentages of $\mathrm{H}_{2} \mathrm{O}(10-100 \%, v / v)$. Operational conditions of both steps $(313 \mathrm{~K}$ and $20 \mathrm{MPa})$ were selected based on the literature information concerning the solubility (in supercritical $\mathrm{CO}_{2}$ ) of the main components of vegetable oils, triglycerides (Bamberger et al. 1988), and on the anthocyanin stability (Jackman et al. 1987). Extracts were concentrated at $313 \mathrm{~K}$, under vacuum and in the absence of light, and kept at $255 \mathrm{~K}$. For the first SFE step, extraction curve was determined in order to define the extraction time that assured a high lipophilic material removal from the plant material. Some ESE assays were duplicated in order to determine the experimental error of the yield values; the others were single. Employed experimental conditions are reported in Table 1.

\section{Thin Layer Chromatography}

TLC analyses were performed using silica gel plates with a $254 \mathrm{~nm}$ fluorescent indicator $(20 \times 20 \mathrm{~cm} \times 0.2 \mathrm{~mm}$; Fluka, Steinheim, Germany). Same extract concentrations were chromatographed. For low polarity compounds analysis, hexane-ethyl acetate $(8: 2, v / v)$ and an anisaldehyde solution (Wagner et al. 1984) were used as the mobile phase and the spray reagent, respectively. For the analysis of phenolic compounds, the mobile phase was ethyl acetate-formic acidglacial acetic acid- $\mathrm{H}_{2} \mathrm{O}(100: 11: 11: 27, v / v)$ solution and a NP solution (MeOH-2-aminoethyl diphenylborinate, 99:1, v/w) was used for detection of phenolic compounds, at $365 \mathrm{~nm}$.

\section{High Performance Liquid Chromatography}

Quantification of anthocyanins and rutin was performed in a Gilson apparatus equipped with a diode-array detector. An ODS-2 column $(250 \times 4.6 \mathrm{~mm}$ i.d., $5 \mu \mathrm{m}$, Spherisorb S5, Waters, MA, USA) at $298 \mathrm{~K}$ and a C18 guard cartridge (30× $4 \mathrm{~mm}$ i.d., $4 \mu \mathrm{m}$, Hichrom, Berkshire, UK) were used. A mobile phase, constituted by aqueous formic acid $(5 \%, v / v)$ (A) and $\mathrm{MeOH}(\mathrm{B})$, was used with a discontinuous gradient of 5-15\% B (0-10 min), 15-25\% B (10-15 min), 25-50\% B (15-40 $\mathrm{min})$ and $50-80 \% \mathrm{~B}(40-50 \mathrm{~min})$, followed by an isocratic elution during $10 \mathrm{~min}$, at a flow rate of $1 \mathrm{~mL} / \mathrm{min}$. 


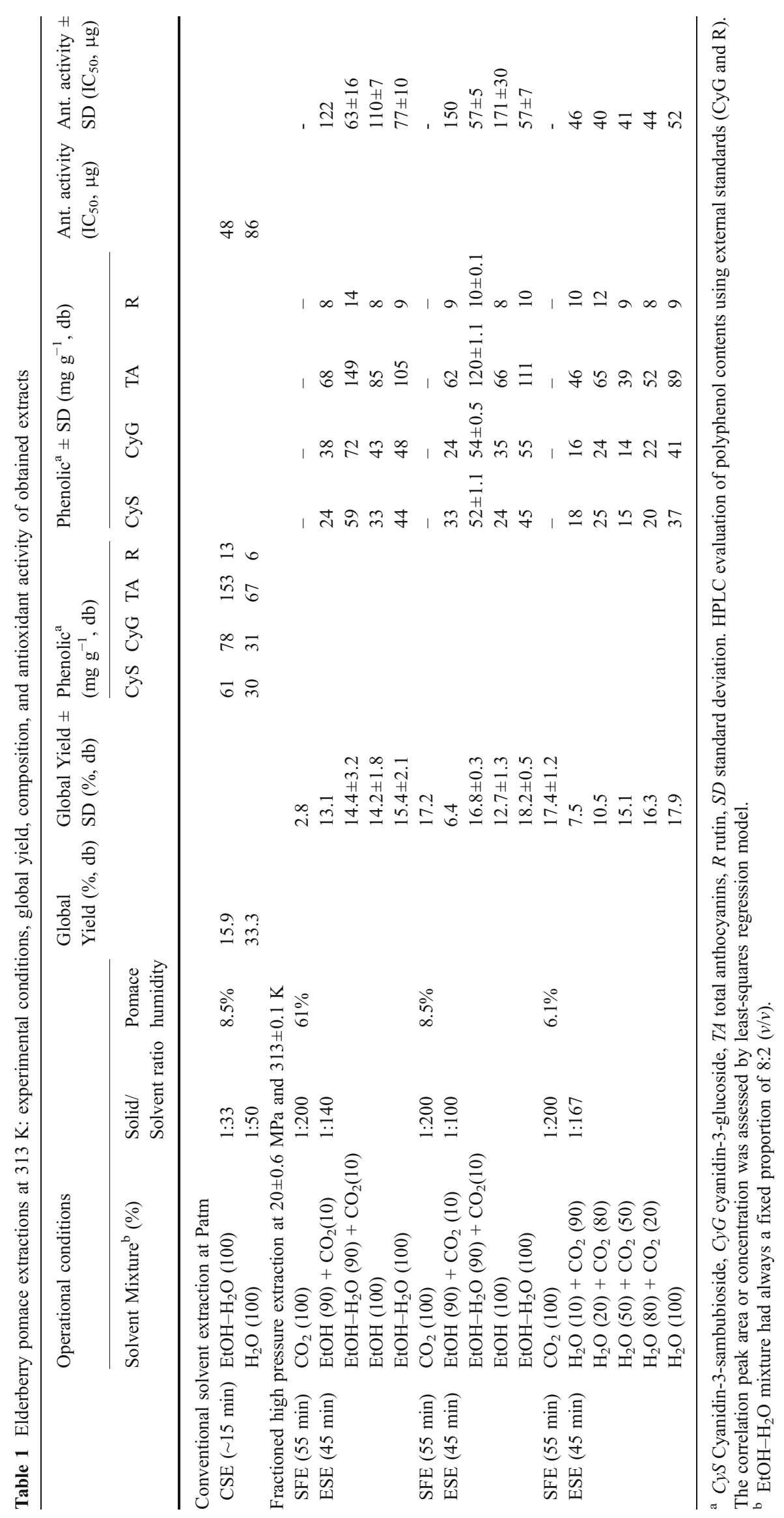




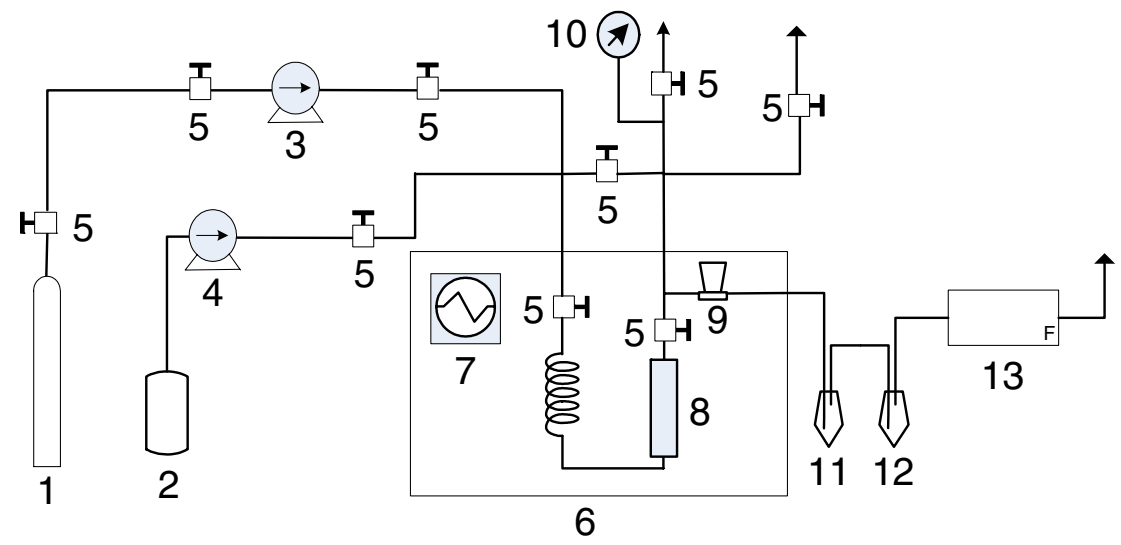

(1) $\mathrm{CO}_{2}$ cylinder

(2) Solvent reservoir

(3) $\mathrm{CO}_{2}$ compressor

(4) High pressure pump

(5) Valves

(6) Thermostatic $\mathrm{H}_{2} \mathrm{O}$ bath

(7) Immersion heater/controller

(8) Extraction cell

(9) Back-pressure regulator

(10) Manometer

(11) Recovering flask

(12) Trap

(13) Flowmeter

Fig. 2 Schematic diagram of the employed high pressure extraction apparatus

Samples were adjusted to $\mathrm{pH} \sim 2$ with $\mathrm{HCl}$ and microfiltered $(0.20 \mu \mathrm{m})$ before HPLC injection. Anthocyanins were identified from their chromatographic and ultraviolet (UV) spectral properties and the major anthocyanins, $\mathrm{CyG}$ and CyS, by comparing with the CyG standard and according to literature data (Brønnum-Hansen and Hansen 1983; Wu et al. 2004). Quantification of anthocyanins (CyS, CyG and total anthocyanins, TA) and rutin (R) was carried out using external standards (CyG and R), at 520 and $360 \mathrm{~nm}$, respectively. The correlation between peak area or concentration was assessed by the least-squares regression model. One of the extracts was injected three times to determine the standard deviation of the assay.

\section{Antioxidant Activity (2,2-diphenyl-1-picrylhydrazyl Assay)}

The antioxidant activity of the extracts was evaluated by using the 2,2-diphenyl-1-picrylhydrazyl (DPPH) method (Blois 1958). Aliquots $(100 \mu \mathrm{L})$ of extracts were added to $500 \mu \mathrm{L}$ of a $\mathrm{MeOH}$ solution $(500 \mu \mathrm{M})$ of DPPH radical in the presence of $100 \mathrm{mM}$ acetate buffer, $\mathrm{pH} 6.0(1 \mathrm{~mL})$, and $\mathrm{MeOH}(1.4 \mathrm{~mL})$. After mixing for $30 \mathrm{~s}$, the reaction mixtures were kept in the dark at room temperature for $30 \mathrm{~min}$, and the absorbance was measured at $517 \mathrm{~nm}$, on a UV-visible spectrophotometer (U-2000, Hitachi, Tokyo, Japan). Triplicate assays were performed. The reducing capacities of the samples were estimated from the observed absorbance decrease and expressed as $\mathrm{IC}_{50}$ values, defined as the amount of elderberry extract [dry basis $(\mathrm{db})$ ] that decreased by $50 \%$, the initial absorbance of the DPPH radical solution, at the referred wavelength.

\section{Calculation Procedures}

Global yields were obtained considering the total extracted mass divided by feed mass in a db. For both high-pressure extraction steps, the total extract mass was determined by the sum of the extract obtained in the recovering flask and trap; for first step, the extract recovered from tubing was also considered. The overall SFE curve was constructed using the accumulated mass of extract, collected at a given extraction time interval. The data was fitted by a curve formed by two lines. The fitting was done by minimizing the least regression error in the least squares sense, using the fmin search function of Matlab (R2007a). The first line was identified with the constant extraction rate period (CER) and the corresponding kinetic parameters were calculated $\left(M_{\mathrm{CER}}, t_{\mathrm{CER}}\right.$, and $\left.Y_{\mathrm{CER}}\right)$, according to Rodrigues et al. (2002).

\section{Results and Discussion}

Elderberry pomace represented around 25\% (w/w, db) of the total fruit weight. Two lots of dry and one lot of in natura pomace were employed, with humidity $[ \pm$ standard deviation (SD)] of $8.5 \pm 0.1,6.1 \pm 0.1$, and $61 \pm 2 \%(w / w, \mathrm{db})$, respectively (Table 1 ).

The elderberry pomace SFE (first step) exhibited a typical overall extraction curve profile (Fig. 3), with $5.3 \times$ $10^{-7} \mathrm{~kg} / \mathrm{s}$ for $M_{\mathrm{CER}}, 12.1 \mathrm{~min}$ for $t_{\mathrm{CER}}$, and $Y_{\mathrm{CER}}$ of $2.0 \times$ $10^{-3}$. For all SFE experiments, extraction was prolonged for $40 \mathrm{~min}$ to guarantee the diffusional period. The mass of extract recovered from tubing cleaning represented $\sim 9 \%$ of the total obtained extract mass in this step. Global yields standard deviation (1.2\%) was calculated from three SFE assays. For ESE (second step) duplicated assays, higher standard deviations (Table 1) were obtained for in natura pomace, probably due to the nonhomogeneity of the solvent and the $\mathrm{H}_{2} \mathrm{O}$ from the raw material.

The obtained global yields are represented in Fig. 4. For fractioned high pressure extractions with ethanolic mixtures in the second step (ESE), higher yields of first + second steps were always obtained for dried elderberry pomace $(\sim 24-35 \%)$ when compared to those using in natura pomace ( $\sim 16-18 \%)$. The main contribution to this difference was 


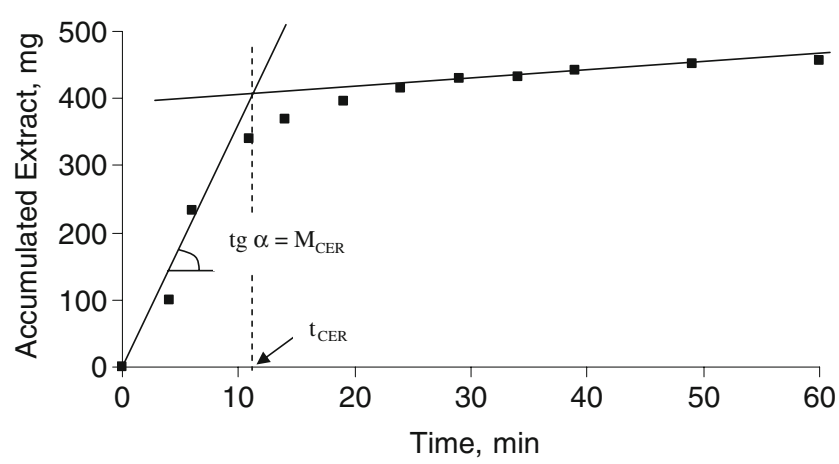

Fig. 3 Kinetics of the first step (SFE) elderberry pomace extraction, at $20.6 \pm 0.6 \mathrm{MPa}$ and $313 \pm 0.1 \mathrm{~K}$, and at a flow rate of $27.3 \times 10^{-5} \mathrm{~kg} \mathrm{~s}^{-1}$

essentially due to the first step, wherein the less polar substances were extracted. This could have happened because for in natura pomace, the seeds were not efficiently comminuted, and $\mathrm{H}_{2} \mathrm{O}$ may have acted as a barrier to diffusion and may have increased the overall polarity of the solvent (Temelli 2000; Reverchon and Marrone 2001). Therefore, drying the byproduct seems to permit a more efficient SFE of low polarity compounds. Since anthocyanins are mainly located in outermost layer of elderberry skin cell walls (Manach et al. 2004) wherein the fatty acids and waxes exist (Pinelo et al. 2006), an effective lipophilic substances removal, in a first-step SFE, can make polar material more available for extraction.

For the second-step ethanolic ESE, the solvent mixture, which was in a single homogeneous phase according to Durling et al. (2007), did not significantly affect global yields for the in natura pomace $(\sim 13-15 \%)$, while they had a greater variation for the dry pomace $(\sim 6-18 \%$; Fig. 4). The initial high in natura material $\mathrm{H}_{2} \mathrm{O}$ content improved the extraction ability of the solvent mixture, suggesting that the presence of $\mathrm{H}_{2} \mathrm{O}$ in the extraction medium could also provide higher yields of more polar compounds, namely anthocyanins, by increasing the solvent mixture density and polarity. In fact, for both raw materials (in natura and dried), the presence of $\mathrm{H}_{2} \mathrm{O}$ in the enhanced ethanolic mixture resulted in an increment in polyphenol contents (anthocyanins and rutin) and in the antioxidant activity of the extracts (Table 1).

The dissolved $\mathrm{CO}_{2}$ negatively affected ESE yields (decrease of 1-7\%); and so, the possible positive influence of the enhanced transport properties of gas-expanded liquids (Chamblee et al. 2004) and the decrease in the solvent mixture $\mathrm{pH}$ were not so significant as the negative influence of the decrease in the solvent polarity that happened when $\mathrm{CO}_{2}$ was added to the solvent (Weikel et al. 2006). However, an increase of TA contents, from 105 to $149 \mathrm{mg} \mathrm{g}^{-1}$ for in natura pomace and from 111 to $120 \mathrm{mg} \mathrm{g}^{-1}$ for dried pomace (Table 1), occurred for the $\mathrm{CO}_{2}-\mathrm{EtOH}-\mathrm{H}_{2} \mathrm{O}$ gas-expanded mixtures; so, not only the higher solvent mixture density and polarity but also the solvent's $\mathrm{pH}$ drop can have important roles in the extraction of these polar substances (West et al. 2001). Therefore, it seems that, for this ternary solvent mixture, $\mathrm{CO}_{2}$ played a similar role as sulfites and weak acids in the conventional solid-liquid extraction of anthocyanins from natural matrixes. In fact, for both raw materials, the highest TA contents and antioxidant activities were obtained when the solvent was the $\mathrm{CO}_{2}-\mathrm{EtOH}-\mathrm{H}_{2} \mathrm{O}$ gas-expanded mixture, presenting in natura pomace similar TA content $\left(149 \mathrm{mg} \mathrm{g}^{-1}\right)$ as the CSE ethanolic extract $\left(153 \mathrm{mg} \mathrm{g}^{-1}\right)$ that was the highest obtained. Similar antioxidant activities were verified for the in natura and the dried pomaces: $\mathrm{IC}_{50}$ of $63 \pm$ 16 and $57 \pm 5 \mu \mathrm{g}$, respectively.

When EtOH- $\mathrm{H}_{2} \mathrm{O}$ was used as the extracting solvent, a $2 \%$ increase in yield was obtained for the ESE relative to the CSE; so, high pressure was more favorable to the extraction yield than simultaneous milling, stirring, and extraction. The lower solid/solvent ratio used in ESE (1:100) when compared to the one used in CSE (1:33) also favored extraction yield. For this solvent mixture $(\mathrm{EtOH}-$ $\left.\mathrm{H}_{2} \mathrm{O}, 8: 2 v / v\right)$, and at these particular conditions of pressure
Fig. 4 Obtained global yields (db) for elderberry pomace extractions. Empty bar SFE$\mathrm{CO}_{2}$; Ethanolic Extracts (filled bar) ESE: $1 \mathrm{EtOH}+\mathrm{CO}_{2}(10 \%)$, $2 \mathrm{EtOH}-\mathrm{H}_{2} \mathrm{O}+\mathrm{CO}_{2}(10 \%), 3$ EtOH, 4 EtOH- $\mathrm{H}_{2} \mathrm{O}$; (dark diagonally striped bar) CSE: 5 EtOH- $\mathrm{H}_{2} \mathrm{O} ;$ Aqueous Extracts (grey bar) ESE: $6 \mathrm{H}_{2} \mathrm{O}+\mathrm{CO}_{2}$ $(90 \%), 7 \mathrm{H}_{2} \mathrm{O}+\mathrm{CO}_{2}(80 \%)$, $8 \mathrm{H}_{2} \mathrm{O}+\mathrm{CO}_{2}(50 \%), 9 \mathrm{H}_{2} \mathrm{O}+$ $\mathrm{CO}_{2}(20 \%), 10 \mathrm{H}_{2} \mathrm{O}$; (light diagonally striped bar) CSE: 11 $\mathrm{H}_{2} \mathrm{O}$

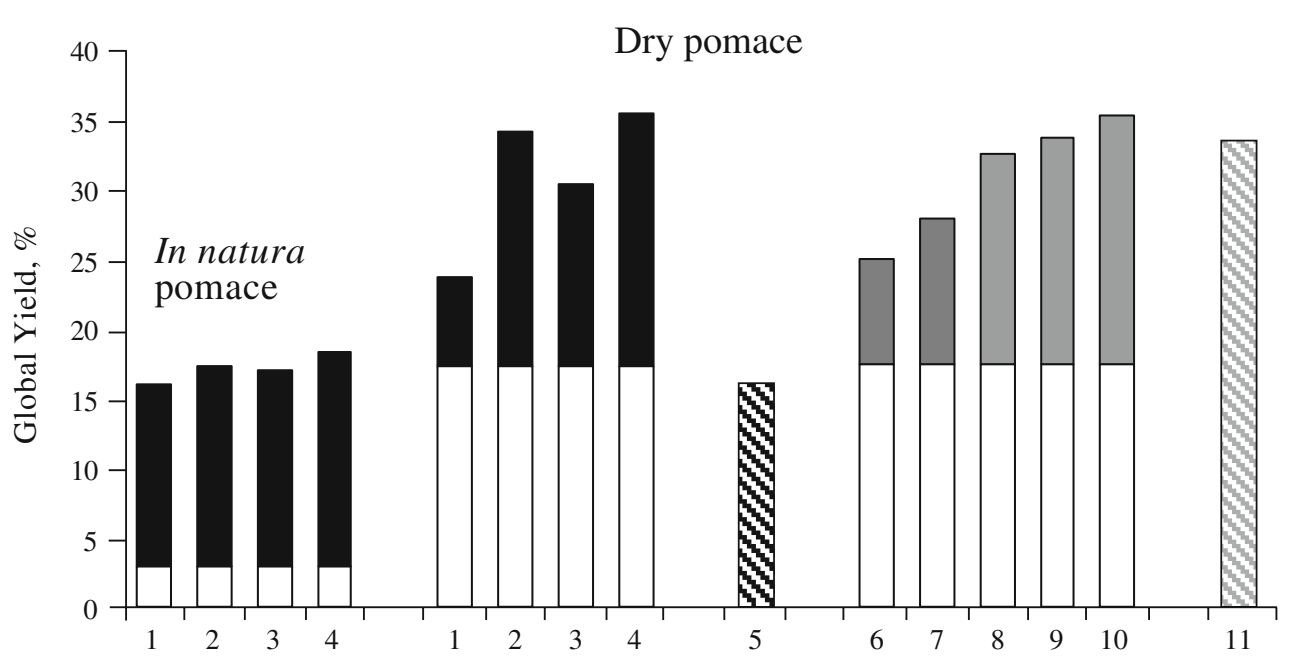


and temperature, ESE seems to be not an advantageous alternative to CSE if the objective is to obtain anthocyaninrich fractions having high antioxidant activities.

Dawidowicz et al. (2006) performed pressurized liquid extraction of $S$. nigra berries, using an $\mathrm{EtOH}-\mathrm{H}_{2} \mathrm{O}(8: 2, v / v)$ mixture as the extracting solvent at $6 \mathrm{MPa}$ and $293 \mathrm{~K}$ and obtained an extract with $\sim 1.1 \mathrm{mg} \mathrm{g}^{-1}$ of rutin and $\sim 5 \mathrm{mg} \mathrm{g}^{-1}$ of $\mathrm{CyS}+\mathrm{CyG}$. The difference between the phenolic compositions in that extract and the ones obtained in this study from elderberry pomace can be related to the different extraction methodologies (no fractionation, lower operational pressure, and temperature) and the raw materials nature.

Because $\mathrm{H}_{2} \mathrm{O}$ seemed to have a positive influence on the observed ESE global yields, this solvent was tested for dry pomace, just employing $\mathrm{CO}_{2}$ and $\mathrm{H}_{2} \mathrm{O}(10-100 \%)$ on the 2nd extraction step. Higher global yields occurred when the $\mathrm{H}_{2} \mathrm{O}$ content was incremented in the ESE solvent mixture (Fig. 4) that increased the relative amount of the $\mathrm{H}_{2} \mathrm{O}$ rich liquid phase (a gas-expanded liquid) but did not change the composition of the two phases present, which remained constant (Perakis et al. 2006). Therefore, the observed raise in ESE yields was just due to an increment in the amount of the high density and polarity phase, which presented a better capacity to dissolve polar substances like anthocyanins. This raise is similar to the one that occurs in conventional solid-liquid extraction when solvent/solid ratio increases (Cacace and Mazza 2002). As happened with the ethanolic solvent, when no $\mathrm{CO}_{2}$ was added, a a

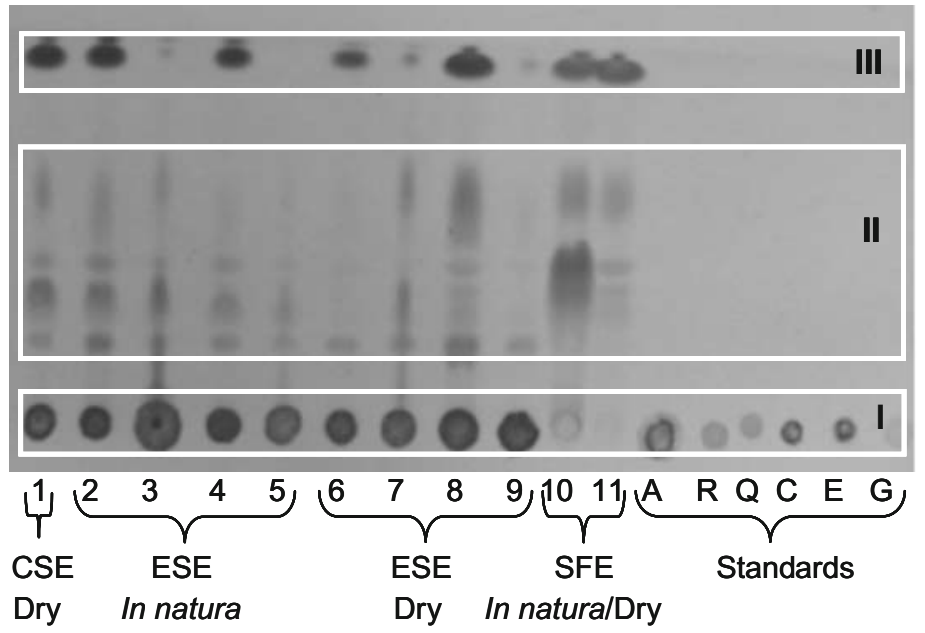

b

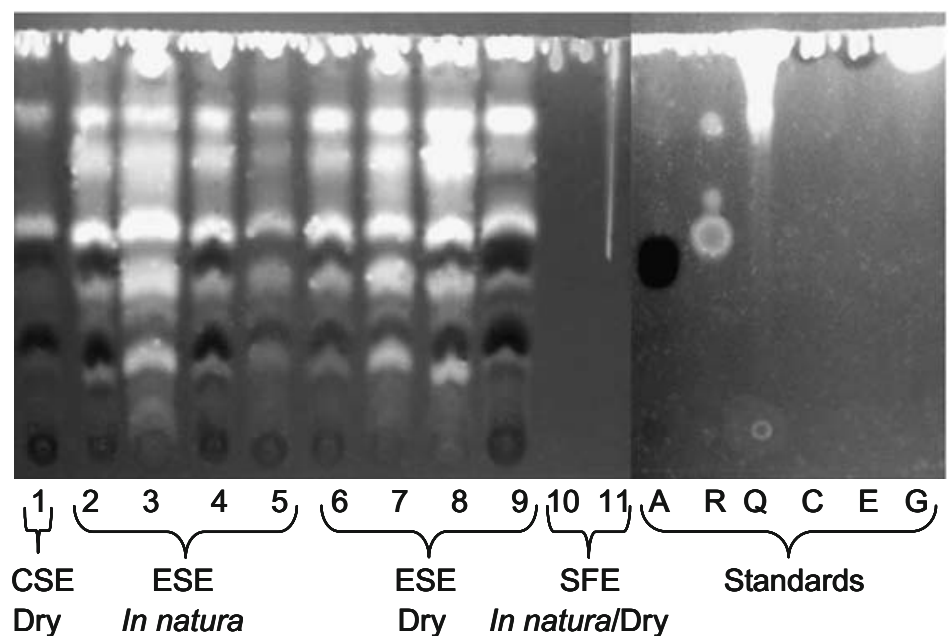

Aqueous and SFE extracts
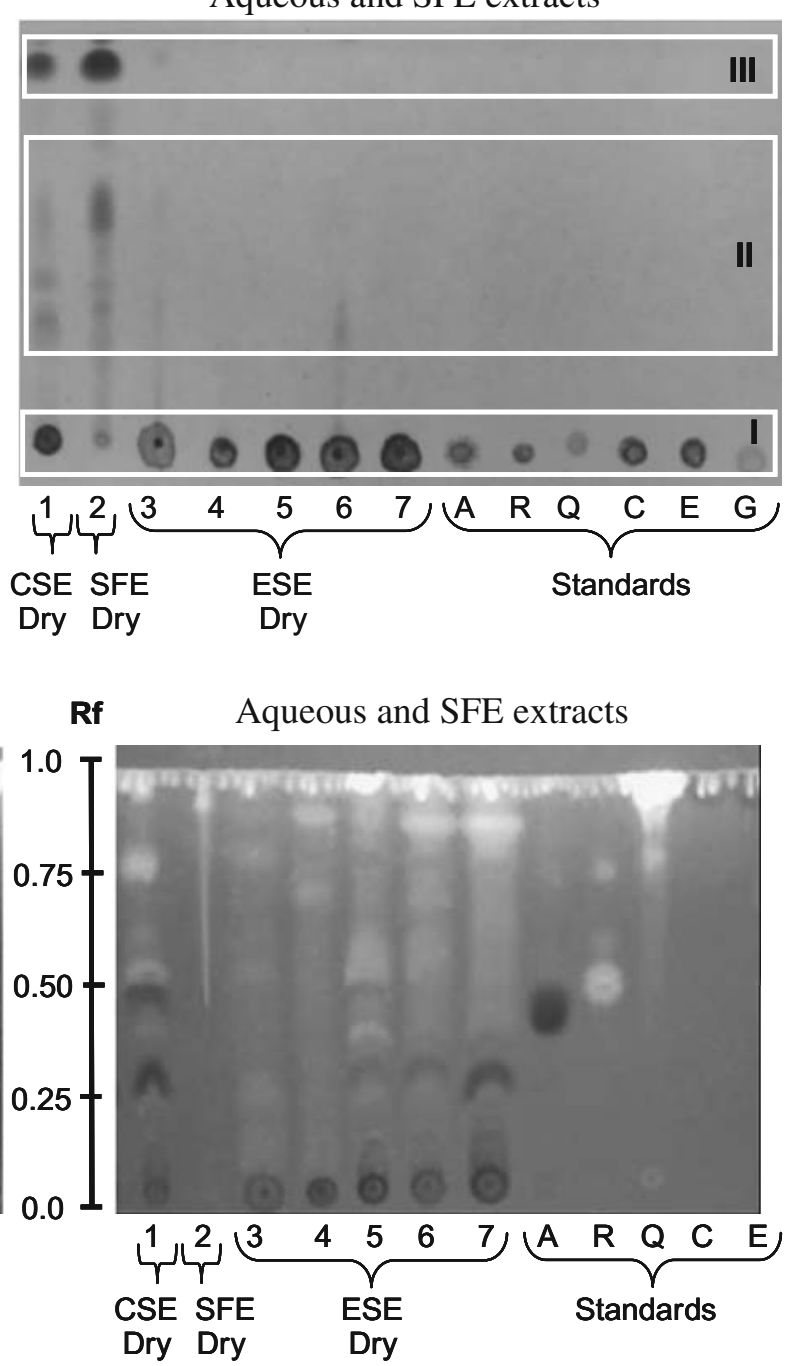

Fig. 5 Analysis of low polarity compounds by anisaldehyde sprayed TLC plates (a) and of high polarity compounds by NP sprayed TLC plates, observed at $365 \mathrm{~nm}$ (b). Conventional extracts at $313 \mathrm{~K}$ and high pressure extracts at $20.6 \pm 0.6 \mathrm{MPa}$ and $313 \pm 0.1 \mathrm{~K}$. Ethanolic and SFE extracts: $1 \mathrm{CSE}-\mathrm{EtOH}-\mathrm{H}_{2} 0 ; 2,6 \mathrm{ESE}-\mathrm{EtOH}+\mathrm{CO}_{2} ; 3,7 \mathrm{ESE}-$
$\mathrm{EtOH}-\mathrm{H}_{2} \mathrm{O}+\mathrm{CO}_{2} ; 4,8 \mathrm{ESE}-\mathrm{EtOH} ; 5,9 \mathrm{ESE}-\mathrm{EtOH}-\mathrm{H}_{2} \mathrm{O} ; 10,11$ $\mathrm{SFE}-\mathrm{CO}_{2}$. Aqueous and SFE extracts: $1 \mathrm{CSE}-\mathrm{H}_{2} \mathrm{0}, 2 \mathrm{SFE}-\mathrm{CO}_{2}, 3$ $\mathrm{ESE}-\mathrm{H}_{2} \mathrm{O}(10 \%), 4 \mathrm{ESE}-\mathrm{H}_{2} \mathrm{O}(20 \%), 5 \mathrm{ESE}-\mathrm{H}_{2} \mathrm{O}(50 \%), 6 \mathrm{ESE}-$ $\mathrm{H}_{2} \mathrm{O}(80 \%), 7 \mathrm{ESE}-\mathrm{H}_{2} \mathrm{O}(100 \%)$. Standards: $A$ Cyanidin 3 -glucoside, $R$ Rutin, $Q$ Quercetin, $C$ Catechin, $E$ Epicatechin, $G$ Gallic acid 
maximum ESE yield was attained $(\sim 18 \%)$, showing a negative $\mathrm{CO}_{2}$ influence on extraction yield.

In contrast, there was not a direct relationship between the $\mathrm{H}_{2} \mathrm{O}$ content in the enhanced solvent mixture and the $\mathrm{TA}$ and rutin extract contents or antioxidant activities. Even though the highest amount of TA $\left(89 \mathrm{mg} \mathrm{g}^{-1}\right)$ was obtained when no $\mathrm{CO}_{2}$ was added to the solvent mixture, the extracts obtained with the $\mathrm{CO}_{2}-\mathrm{H}_{2} \mathrm{O}$ gas-expanded liquid showed higher antioxidant activities ( $\left.\mathrm{IC}_{50} 40-46 \mu \mathrm{g}\right)$. These results suggest that the $\mathrm{pH}$ drop that followed the possible carbonic acid formation [pH may decrease down to 2.8 , according to Towes et al. (1995)] did not influence positively the amount of extracted anthocyanins but possibly influenced their stability, once these pigments are known to be at the most stable state at $\mathrm{pH} 1$ to 3 (Delgado-Vargas and ParedesLópez 2003). In fact, ESE aqueous extracts $\mathrm{IC}_{50}$ values were close to the ethanolic CSE value $(48 \mu \mathrm{g})$, despite having around three times less anthocyanins. However, rutin contents and other eventually extracted substances, like proanthocyanidins, may have also contributed to the extracts antioxidant activity.

Comparing the aqueous extraction methodologies, and in opposite to what happened with the ethanolic experiments, extraction from a nondefatted raw material and simultaneous milling and extraction was more favorable to extraction yield than high pressure (Table 1). Although, the obtained high CSE yield was due to the coextraction of compounds that did not contribute to the extract antioxidant activity as is confirmed when TA and rutin contents (67 and $6 \mathrm{mg} \mathrm{g}^{-1}$ respectively), and antioxidant activity $\left(\mathrm{IC}_{50}\right.$ $86 \mu \mathrm{g})$ are compared to ethanolic CSE ones (153 and $13 \mathrm{mg} \mathrm{g}^{-1}$, respectively, and $\mathrm{IC}_{50} \sim 48 \mu \mathrm{g}$ ).

The presence of low polarity compounds in extracts was monitored by using anisaldehyde sprayed TLC plates (Fig. 5a). For ESE, the presence of zones that migrated with the solvent (II and III) in some extracts indicates that lipophilic compounds were not completely extracted during
SFE. The lipophilic composition of these extracts varied with the nature of the employed solvent, being almost absent in aqueous extracts (Fig. 5a). Strong zones at the solvent front (III) appeared in those ESE ethanolic extracts in which $\mathrm{H}_{2} \mathrm{O}$ was not used in the solvent mixture, which means that the presence of $\mathrm{H}_{2} \mathrm{O}$ avoided the coextraction of high lipophilic compounds, playing an anti-solvent role. Despite the fact that the low polarity substances were not completely extracted, TLC analysis was an indication that $\mathrm{CO}_{2}$ SFE was capable of extracting lipophilic or low polarity compounds, which resulted in the concentration of phenolic compounds and other polar substances in the vegetal matrix for the subsequent extraction step.

The overall phenolic composition of the extracts was monitored by using NP sprayed TLC plates (Fig. 5b). Several zones appeared in both ethanolic and aqueous CSE and ESE extracts, with higher intensity for the ethanolic ones: two main dark blue zones with Rf 0.28 and 0.48 (CyG), five weaker light blue zones (corresponding to non identified anthocyanins), two orange fluorescent zones at Rf 0.55 (R) and at $\mathrm{Rf} 0.8$ that may correspond to quercetin glycosides, and two light blue fluorescents that may be assigned to phenol carboxylic acids (Wagner et al. 1984), among others. The other standards used in the analysis appeared at the solvent front and were not identified in extracts.

For most extracts, the major anthocyanin was found to be $\mathrm{CyG}$, and the sum of $\mathrm{CyS}$ and $\mathrm{CyG}$ contents represented around $90 \%$ of the TA contents (Table 1, Fig. 6). These results are similar to those already reported in literature for elderberries (Wu et al. 2004). In general, there was not a direct relationship between TA contents and antioxidant activity of the extracts, which is in agreement with the results obtained by Kähkönen et al. (2001) and Nakajima et al. (2004) for berry extracts obtained by CSE, using different solvents. There was not an evident and direct relationship between rutin contents and the antioxidant activity of the extracts, either, although extracts with higher
Fig. 6 HPLC profile of in natura elderberry pomace extract obtained by ESE using EtOH $(90 \%)+\mathrm{CO}_{2}(10 \%)$, at $313 \mathrm{~K}$ and $\sim 20 \mathrm{MPa}$ recorded at $520 \mathrm{~nm}$. Peaks: 1 and 2 anthocyanins; 3 cyanidin 3 -sambubioside; 4 cyanidin 3-glucoside; 5 quercetin glycoside; 6 rutin

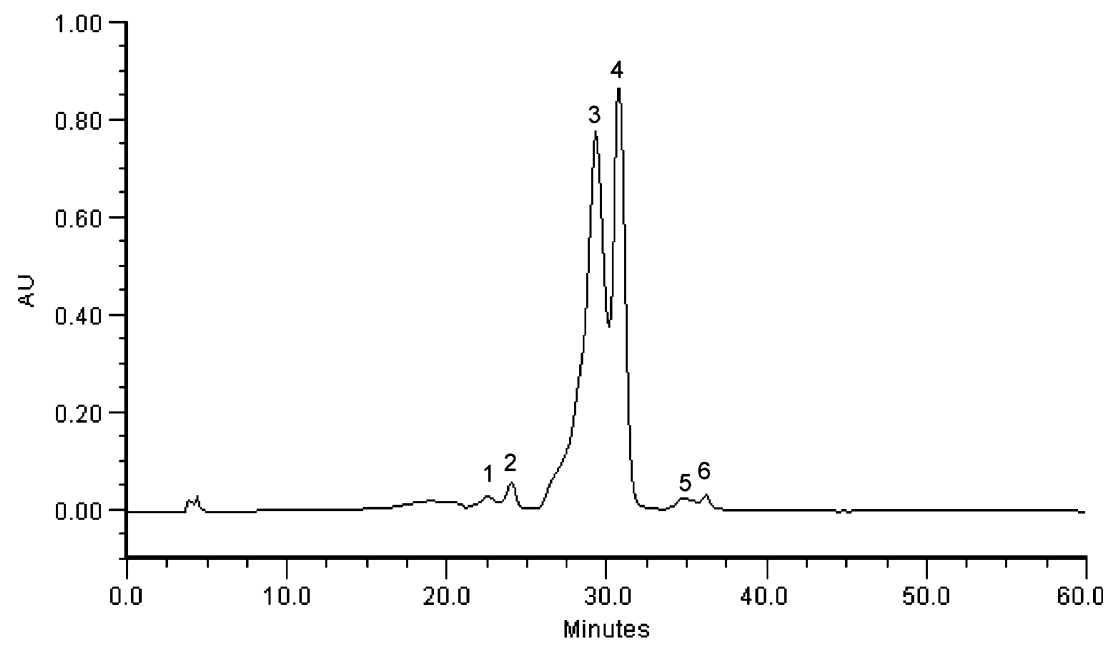


antioxidant activity (aqueous ESE $\left(20 \% \mathrm{H}_{2} \mathrm{O}\right)-\mathrm{IC}_{50}$ of $40 \mu \mathrm{g}$, and ethanolic $\mathrm{CSE}-\mathrm{IC}_{50}$ of $48 \mu \mathrm{g}$ ) were among the ones with higher rutin contents. These results are in accordance with the fact that the relationship between antioxidant activity of berry extracts and their phenolic composition is complex (Kähkönen et al. 2001) and, in addition, synergism can have a significant effect on the antioxidant response of plant extracts.

Total anthocyanin content in the elderberry pomace extracts obtained in this work $\left(39-153 \mathrm{mg} \mathrm{g}^{-1}\right.$ ) were considerably higher than total anthocyanin content in the dry red grape skin extracts $\left(41-57 \mathrm{mg} \mathrm{g}^{-1}\right)$, obtained by $\mathrm{Ju}$ and Howard (2003) and using different solvents (acidified alcohols, $\mathrm{H}_{2} \mathrm{O}$ and acetone mixtures) at $323 \mathrm{~K}$ and 10.1 MPa. This is probably the best anthocyanin content that can be obtained using grape pomace as raw material, since the authors claim that the employed grape variety was exceptionally rich in TA and, like in elderberry pomace, these were more concentrated in grape skin than in the whole grape. These results show that elderberry pomace is a very good source of anthocyanins when compared to wine industry byproducts.

\section{Conclusions}

Anthocyanin rich elderberry pomace extracts were obtained, employing a fractioned high pressure methodology. During the first step $\mathrm{CO}_{2}$ SFE that was more efficient for the dry raw material, essentially lipophilic compounds were extracted. For ethanolic ESE assays, the presence of $\mathrm{H}_{2} \mathrm{O}$ in the solvent mixture resulted in an increment in global yields and in TA contents with a consequent improvement in the extracts antioxidant activity. Moreover, for the ESE assays using EtOH- $\mathrm{H}_{2} \mathrm{O}$ in the solvent mixture, the dissolved $\mathrm{CO}_{2}$ favored TA contents and antioxidant properties. For the aqueous ESE assays, even though global yields increased with the $\mathrm{H}_{2} \mathrm{O}$ content increase in the solvent mixture, there was not a direct relationship with TA contents or antioxidant capacities. Antioxidant activity of these aqueous ESE extracts were high and comparable to the ethanolic CSE extract, despite their low TA and phenolic (observed by TLC) contents.

Relatively to the methodology used, ESE has several additional advantages over CSE, such as the possibility of extract fractionation and a higher extraction flexibility, which is offered by the possibility of modifying solvent dissolution capability just by changing operational conditions as dissolved $\mathrm{CO}_{2}$, and temperature and pressure, which can also be explored.

The presented results clearly indicate that it is possible to obtain anthocyanin rich extracts from elderberry pomace possessing high antioxidant activity and, in this way, adding economical value to this agroindustrial residue. These was done using solvents and techniques considered as "acceptable" and "generally regarded as safe" in the food and pharmaceutical industries.

Acknowledgments The authors are grateful to Cooperativa Agrícola do Vale do Varosa (Portugal), for providing the raw material, and to Programa Iberoamericano de Ciencia y Tecnología para el Desarollo for technical support of the Aplicaciones Industriales de los Taninos Vegetales Project.

\section{References}

Bamberger, T., Erickson, J. C., Cooney, C. L., \& Kumar, S. K. (1988). Measurement and model prediction of solubilities of pure fatty acids, pure tryglicerides, and mixtures of tryglicerides in supercritical carbon dioxide. Journal of Chemical and Engineering Data, 33(3), 327-333. doi:10.1021/je00053a029.

Bermúdez-Soto, M. J., \& Tomás-Barberán, F. A. (2004). Evaluation of commercial red fruit juice concentrates as ingredients for antioxidant functional juices. European Food Research and Technology, 219, 133-141. doi:10.1007/s00217-004-0940-3.

Blois, M. S. (1958). Antioxidant determinations by the use of a stable free radical. Nature, 181, 1199-1200. doi:10.1038/1811199a0.

Braga, F. G., Carvalho, L. M., Carvalho, M. J., Guedes-Pinto, H., Torres-Pereira, J. M., Neto, M. F., et al. (2002). Variation of the anthocyanin content in Sambucus nigra L. Populations growing in Portugal. Journal of Herbs, Spices \& Medicinal Plants, 9(4), 289-295. doi:10.1300/J044v09n04_05.

Brønnum-Hansen, K., \& Hansen, S. $\bar{H}$. (1983). High-performance liquid chromatographic separation of Sambucus nigra L. Journal of Chromatography A, 262, 385-392. doi:10.1016/S0021-9673 (01)88125-5.

Brønnum-Hansen, K., Jacobsen, F., \& Flink, J. M. (1985). Anthocyanin colourants from elderberry (Sambucus nigra L.). 1. Process considerations for production of the liquid extract. Journal of Food Technology, 20(6), 703-711.

Cacace, J. E., \& Mazza, G. (2002). Extraction of anthocyanins and other phenolics from black currants with sulfured $\mathrm{H}_{2} \mathrm{O}$. Journal of Agricultural and Food Chemistry, 50(21), 5939-5946. doi:10.1021/jf025614x.

Chamblee, T. S., Weikel, R. R., Nolen, S. A., Liotta, C. L., \& Eckert, C. A. (2004). Reversible in situ acid formation for $\beta$-pinene hydrolysis using $\mathrm{CO}_{2}$ expanded liquid and hot $\mathrm{H}_{2} \mathrm{O}$. Green Chemistry, 6, 382-386. doi:10.1039/b400393d.

Dawidowicz, A. L., Wianowska, D., \& Baraniak, B. (2006). The antioxidant properties of alcoholic extracts from Sambucus nigra L. (antioxidant properties of extracts). LWT-Food Science and Technology, 39, 308-315.

Delgado-Vargas, F., \& Paredes-López, O. (2003). Natural colorants for food and nutraceutical uses. Boca Raton: CRC (e-book).

Díaz-Reinoso, B., Moure, A., Domínguez, H., \& Parajó, J. C. (2006). Supercritical $\mathrm{CO}_{2}$ extraction and purification of compounds with antioxidant activity. Journal of Agricultural and Food Chemistry, 54(7), 2441-2469. doi:10.1021/jf052858j.

Durling, N. E., Catchpole, O. J., Tallon, S. J., \& Grey, J. B. (2007). Measurement and modelling of the ternary phase equilibria for high pressure carbon dioxide-ethanol-water mixtures. Fluid Phase Equilibria, 252, 103-113. doi:10.1016/j.fluid.2006.12.014.

Foster, N., Mammucari, R., Dehghani, F., Barrett, A., Bezanehtak, K., Coen, E., et al. (2003). Processing pharmaceutical compounds using dense gas technology. Industrial \& Engineering Chemistry Research, 42(25), 6476-6493. doi:10.1021/ie030219x. 
Garcia-Palazon, A., Suthanthangjai, W., Kajda, P., \& Zabetakis, I. (2004). The effects of high hydrostatic pressure on $\beta$-glucosidase, peroxidase and polyphenoloxidase in red raspberry (Rubus idaeus) and strawberry (Fragaria $\times$ ananassa). Food Chemistry, 88, 7-10. doi:10.1016/j.foodchem.2004.01.019.

Jackman, R. L., Yada, R. Y., Tung, M. A., \& Speers, R. A. (1987). Anthocyanins as food colorants - a review. Journal of Food Biochemistry, 11(3), 201-247. doi:10.1111/j.1745-4514.1987.tb00123.x.

Ju, Z. Y., \& Howard, L. R. (2003). Effects of solvent and temperature on pressurized liquid extraction of anthocyanins and total phenolics from dry red grape skin. Journal of Agricultural and Food Chemistry, 51(18), 5207-5213. doi:10.1021/jf0302106.

Kähkönen, M. P., Hopia, A. I., \& Heinonen, M. (2001). Berry phenolics and their antioxidant activity. Journal of Agricultural and Food Chemistry, 49(8), 4076-4082. doi:10.1021/jf010152t.

Kamat, S. V., Beckman, E. J., \& Russell, A. J. (1995). Enzyme activity in supercritical fluids. Critical Reviews in Biotechnology, 15, 41-71. doi:10.3109/07388559509150531.

Manach, C., Scalbert, A., Morand, C., Rémésy, C., \& Jiménez, L. (2004). Polyphenols: Food sources and bioavailability. American Journal of Clinical Nutrition, 79, 727-747.

Nakajima, J., Tanaka, I., Seo, S., Yamazaki, M., \& Saito, K. (2004). LC/PDA/ESI-MS profiling and radical scavenging activity of anthocyanins in various berries. Journal of Biomedicine and Biotechnology, 5, 241-247. doi:10.1155/S1110724304404045.

Neto, F. C., \& Monteiro, A. M. (2002). Sabugueiro uma cultura alternativa. Mirandela: Ficha Técnica. DRATM.

Norton, T., \& Sun, D. (2008). Recent advances in the use of high pressure as an effective processing technique in the food industry. Food and Bioprocess Technology, 1, 2-34. doi:10.1007/s11947-007-0007-0.

Pasquel, A., Meireles, M. A. A., Marques, M. O. M., \& Petenate, A. J. (2000). Extraction of stevia glycosides with $\mathrm{CO}_{2}+\mathrm{H}_{2} \mathrm{O}, \mathrm{CO}_{2}+\mathrm{EtOH}$, and $\mathrm{CO}_{2}+\mathrm{H}_{2} \mathrm{O}+\mathrm{EtOH}$. Brazilian Journal of Chemical Engineering, 17(3), 271-282. doi:10.1590/S0104-66322000000300003.

Perakis, C., Voutsas, E., Magoulas, K., \& Tassios, D. (2006). Thermodynamic modeling of the vapor-liquid equilibrium of the $\mathrm{H}_{2} \mathrm{O} / \mathrm{EtOH} / \mathrm{CO}_{2}$ system. Fluid Phase Equilibria, 243, 142150. doi:10.1016/j.fluid.2006.02.018.

Pinelo, M., Arnous, A., \& Meyer, A. S. (2006). Upgrading of grape skins: Significance of plant cell-wall structural components and extraction techniques for phenol release. Trends in Food Science \& Technology, 17, 579-590. doi:10.1016/j.tifs.2006.05.003.

Reverchon, E. (1997). Supercritical fluid extraction and fractionation of essential oils and related products. Journal of Supercritical Fluids, 10, 1-37. doi:10.1016/S0896-8446(97)00014-4.
Reverchon, E., Daghero, J., Marrone, C., Mattea, M., \& Poletto, M. (1999). Supercritical fractional extraction of fennel seed oil and essential oil: Experiments and mathematical modeling. Industrial \& Engineering Chemistry Research, 38(8), 3069-3075. doi:10.1021/ie990015+.

Reverchon, E., \& Marrone, C. (2001). Modeling and simulation of the supercritical $\mathrm{CO}_{2}$ extraction of vegetable oils. Journal of Supercritical Fluids, 19, 161-175. doi:10.1016/S0896-8446(00) 00093-0.

Rodrigues, V. M., Sousa, E. M. B. D., Monteiro, A. R., ChiavoneFilho, O., Marques, M. O. M., \& Meireles, M. A. A. (2002). Determination of the solubility of extracts from vegetable raw material in pressurized $\mathrm{CO}_{2}$ : A pseudo-ternary mixture formed by cellulosic structure + solute + solvent. Journal of Supercritical Fluids, 22, 21-36. doi:10.1016/S0896-8446(01)00108-5.

Temelli, F. (2000). Lipid extraction from plant and muscle tissues using supercritical $\mathrm{CO}_{2}$. In E. Kiran, P. Debenedetti, \& C. Peters (Eds.), Supercritical fluids, fundamentals and applications (pp. 489-498). Dordrecht: Kluwer Academic.

Towes, K. L., Shroll, R., Wai, C. M., \& Smart, N. G. (1995). pHdefining equilibrium between water and supercritical $\mathrm{CO}_{2}$. Influence on SFE of organics and metal chelates. Analytical Chemistry, 67(22), 4040-4043. doi:10.1021/ac00118a002.

Türker, N., \& Erdoğdu, F. (2006). Effects of $\mathrm{pH}$ and temperature of extraction medium on effective diffusion coefficient of anthocyanin pigments of black carrot (Daucus carota var. L.). Journal of Food Engineering, 76, 579-583. doi:10.1016/j.jfoodeng. 2005.06.005.

Wagner, H., Bladt, S., \& Zgainski, E. M. (1984). Plant drug analysis. A thin layer chromatography atlas. Berlin: Springer.

Weikel, R. R., Hallett, J. P., Liotta, C. L., \& Eckert, C. A. (2006). Selfneutralizing in situ acid catalysts from $\mathrm{CO}_{2}$. Top Catal, 37(2-4), 75-80. doi:10.1007/s11244-006-0007-8.

West, K. N., Wheeler, C., McCarney, J. P., Griffith, K. N., Bush, D., Liotta, C. L., et al. (2001). In situ formation of alkylcarbonic acids with $\mathrm{CO}_{2}$. Journal of Physical Chemistry A, 105(16), 3947-3948. doi:10.1021/jp003846y.

Wu, X., Gu, L., Prior, R., \& McKay, S. (2004). Characterization of anthocyanins and proanthocyanins in some cultivars of ribes, aronia, and sambucus and their antioxidant capacity. Journal of Agricultural and Food Chemistry, 52(26), 7846-7856. doi:10.1021/jf0486850.

Yuan, H., \& Olesik, S. V. (1997). Supercritical and enhanced-fluidity liquid extraction of phenolics from river sediment. Journal of Chromatography A, 764, 265-277. doi:10.1016/S0021-9673(96)00896-5. 